\title{
Secondhand tobacco smoke exposure of infants at home: A population based cross-sectional study
}

\author{
Binali Catak ${ }^{\mathrm{a}}$, Can Oner ${ }^{\mathrm{b}, *}$, Sevinc Sutlu ${ }^{\mathrm{c}}$ \\ ${ }^{a}$ Kafkas University School of Medicine, Department of Public Health, Kars, Turkey \\ ${ }^{\mathrm{b}}$ Kartal Dr Lutfi Kirdar Research and Training Hospital, Department of Family Medicine, Istanbul, Turkey \\ ${ }^{\mathrm{c}}$ Burdur Directory of Health, Burdur, Turkey
}

\section{A R T I C L E I N F O}

\section{Keywords:}

Passive smoking

Environmental smoke

Second hand smoke

Infants

\begin{abstract}
A B S T R A C T
Introduction: Secondhand smoke exposure is one of the important public health problems especially infants and children. The aim of this study was to assess prevalence and social predictors of secondhand smoke exposure of newborns and infants in household.

Methods: A cross sectional study conducted with a sample of 763 infants from 1 June to 31 August 2012 in Burdur. A questionnaire developed by was used for this study. It includes questions about socio- and bio-demographic features of participants and smoking related data by self reports of participants. Second hand smoke exposure of infants was considered as smoking someone at least one day per a week in the house.

Results: Secondhand smoke exposure prevalence of infants was $64 \%$ in Burdur. It was found that five factors including mothers' education level, family type, mothers' smoking status, infants' age and fathers' smoking status were related with infants' second hand smoke exposure.

Conclusion: The rate of secondhand smoke exposure of infants at home is very high. The most important factor affecting second hand smoke exposure was parents'; especially fathers' smoking status. Therefore parents should be encouraged to quit smoking.
\end{abstract}

\section{Introduction}

Involuntary exposure and inhalation of other persons' tobacco smoke is called "passive smoking", "environmental tobacco smoke" or "secondhand smoke exposure (SHSE) ". ${ }^{1}$ Secondhand smoke is a mixture of gases and fine particles include many types of chemicals including nicotine, carbon dioxide, carbonmonxide etc. ${ }^{2}$ According to" World Health Organization's Global Youth Tobacco Survey" which reports 43 different countries a median of $49 \%$ of SHSE rate wa found out. $^{3}$

Secondhand smoke exposure begins in utero with maternal smoking and continues throughout the life. Exposure to SHS at home is an important preventable cause of morbidity and mortality in children. The negative effect of SHS on children's health has been shown in previous studies. SHSE is directly associated to respiratory illnesses, abnormal pulmonary function, asthma, middle ear diseases and deficit hyperactivity disorders. ${ }^{4}$ Recent studies also reveal the cardiovascular effects of SHSE whose consequences may persist into adult life. ${ }^{5}$ In the case of SHS exposure, it is very important to protect children, especially infants and newborns. They have higher respiratory rates so the impact of SHS exposure is more significant. Moreover, their organs' sensitivity for air pollutants, like SHS, is high due to growth and maturation process. Immature detoxification systems of infants also make them more sensitive. ${ }^{6}$ Compared to children, adolescents and adults, infants and newborns have no control over household environment and spend most of their time in closed rooms. ${ }^{7}$

On the field of SHSE some racial and socioeconomical status (SES) disparities persists. Children's SHS exposure is related mainly with social factors. Social predictors of SHSE at home were grouped as five categories: socio-economic status (income, employment, education, health insurance etc); parental characteristics (education, age etc); parental smoking behaviors; child's characteristics (age, gender etc.) and family and home characteristics (family size, home environment etc.). ${ }^{8}$ In a study it was shown that the SHSE rate of individuals living below poverty level was significantly higher than those living above the poverty level (\%43,2 vs \%21.2). ${ }^{9}$ Families' socio-economic position and parental smoking behaviors are the two key determinants of all these predictors. ${ }^{6}$ Lower socio-economical status significantly correlated with smoking habits; therefore children's SHS exposure is higher in families with low socio-economical status. ${ }^{10}$ It was shown that children of

\footnotetext{
* Corresponding author.

E-mail address: drcanoner@gmail.com (C. Oner).
} 
parents in low social classes were more likely exposed to SHS up to 3 times. $^{8}$

Tobacco use is common in Turkey. The rate of daily smoking adults is $33.8 \%$ and smoking prevalence is higher among men (\%52.9 vs $19.5 \%)$. Smoking habit is common in urban areas and in contrast to developed countries smoking is more prevalent among educated group. ${ }^{11}$ Based on national studies $81.6 \%$ of school children (8-10 years of age) were exposed secondhand smoke in their homes and this rate reaches up to $85.9 \%$ in public areas. ${ }^{12}$ The aim of this study was to assess prevalence and social predictors of SHS exposure of newborns and infants in household. To our knowledge, this study is one of the first national studies evaluating SHS exposure of infants' and newborns'. The results of this study will enable the policy makers to understand the prevalence of SHS exposure in children and also elucidate the social groups under the risk of exposure.

\section{Methods}

The study conducted in Burdur. Burdur is a city located in Mediterranean region of Turkey and consisting of 11 municipalities and has a population nearly 257267 . Most of the population lives in metropolitan area $(64.5 \%)$ and $35.5 \%$ of population is rural population. The median age of the city is 36.5 ; the rate of young population is $27.5 \%$. Crude birth rate of Burdur is 11.5 per thousand and 2.945 new deliveries take place within 2012. Infant mortality rate is 8.8 per thousand. There are 3 state and one private hospital and 78 primary care units.

The data of the study were obtained from a cross-sectional survey. All of the women who were delivered between 1 June-31 August 2012 ( $n=816$ ) were the sample of the study. No sampling was selected and it was aimed to reach the entire universe. There was nobody refused to participate in the study. Ninety-three percent $(n=763)$ of the universe was reached. The most prominent reasons for inability to reach women were absence at the address $(n=25)$; permanent migration $(n=13)$ and temporary visit to their parents $(n=15)$. Data was collected by face to face interview technique after getting verbal consent from women with a questionnaire developed by researches. This questionnaire includes questions about socio- and bio-demographic status of participants. All of the smoking related data were self report. Participants that have not smoked in their lifetime or smoked but do not smoke currently (at least for last 1 month) were defined as "nonsmoker". If someone smokes at home least one day per a week it was considered as SHS exposure of infants.

Bivariate associations between SHS exposure and risk factors were examined. The data were analyzed using SPSS 20.0 package program. Descriptive statistics were generated for all variables. Frequencies, percentages, mean, standard deviation, median, maximum and minimum values were used as descriptive measures. Bivariable analyses were conducted using chi-squared analysis. Multiple logistic regression analysis was performed to assess the impact of these variables on SHS exposure. A two-sided $\mathrm{p}$ value less than 0.05 was considered statistically significant.

\section{Results}

A total of 816 infants were planned to be included, but only $93.5 \%$ of eligible infants were reached. The mean age of infants was 116 ( \pm 36.9 ) days. Secondhand smoke exposure rate of infants was $64.0 \%$. The smoking rates of mothers and fathers reach up to $9.3 \%(n=71)$ and $60.9 \%(n=465)$, respectively. The most frequently used places for smoking in the house were balconies (75.9\%), kitchens (27.1\%), other rooms $(21.5 \%)$ and toilets/bathrooms (5.8\%).

Participants' socio-demographic characteristics were summarized in Table 1. There were statistically significant difference between SHS exposure of infants and family income $(p=0.029)$, consanguineous marriage $(\mathrm{p}=0.026)$, education level $(\mathrm{p}=0.003)$ and employment
( $\mathrm{p}=0.001)$ status of mothers. Infants were exposed to SHS more in extended families; $72.2 \%(\mathrm{n}=92)$ of infants live in extended families had SHS exposure. Infants in families with low economical classes and lack of health insurance were more frequently exposed to SHS ( $\mathrm{p}=0.017$ and 0.026 , respectively).

We found that SHS exposure was significantly related with increased age of infants and parents' smoking status. The SHS exposure rate of infants with the age of $\geq 5$ months was $70.3 \%(n=116)$ whereas it reaches up to $56.6 \%(n=112)$ in infants $\leq 2$ months of age. Ninety percent of infants that were exposed to SHS had smoking mothers and $84.3 \%$ had smoking fathers (Table 2).

The results of multiple logistic regression analysis were shown in Table 3. Five factors including mothers' education level, family type, mothers' smoking status, infants' age and fathers' smoking status were related with infants' SHS exposure. SHS exposure was 1.7 (CI 1.2-2.4) fold more in infants whose mothers' education duration was below 8 years. Compared with core families, SHS exposure of infants was 1.9 fold more (CI 1.1-3.1) in extended families. SHS exposure was dramatically increases and reaches 11.3 (CI 7.8-16.2) fold more in infants with a smoking father and also 5.0 fold more (CI2.1-12.1) with a smoking mother. If the infants with the age of $\leq 2$ months were taken as reference, SHS exposure was 2.1 times more (CI: $1.2-3.5$ ) in infants $\geq 5$ months of age (Table 3 ).

\section{Discussion}

This study aimed to determine the prevalence and related factors of SHS exposure in infants. Infants' SHS exposure at home were associated with mothers'-fathers' smoking status, mother's educational level, family type and infants' age and the prevalence was $64.0 \%$. Our findings indicate a very high prevalence of SHS exposure of infants at home and consistent with the national data which report the SHS exposure of infants between $59.9 \%$ and $89.0 \%$ in different studies. ${ }^{12-14}$ Overall the world, SHS exposure of children at home was reported as $40 \%$, it is low in Africa (12-13\%), and it ranges between $22 \%$ and $29 \%$ in America, very high in Pacific region $(51-67 \%){ }^{15}$

It was found that $9,6 \%$ of mothers and $62,2 \%$ or fathers were smoking. Moreover parents declare that they smokes at home in areas where the child is no presents, most the time they smoke at balconies $(75,9 \%)$, kitchens $(27,1 \%)$ and bathrooms/toilets $(5,8 \%)$. We found high SHSE rates because we accept SHSE if any one smokes at home at least one day per week. In a recent study it was shown that children whose parents have reported that they do not smoke in the presence of children in the room had higher cotinine levels than whose house there are no smokers. So this finding is speculated as an indicator of the impact of smoke on household. Moreover the researches mark also the non reliability of the declaration of the parents. ${ }^{13}$

In bivariate analyses it was found that secondhand smoke exposure of infants at home was very strongly associated with parents' smoking status. It was found that SHS exposure of infants was 11.3 (CI 7.8-16.2) times more if father smokes and 5.0 times more (CI2.1-12.1)) if mother smokes. Most of the national and international studies showed this relationship. Ulbricht et al. reported that SHS exposure was 2.92 times more if both of parents smoked and it was 3.15 times more if only one of the parents smoked. ${ }^{16}$ In a systemic review on predictors of children's SHS exposure at home it was concluded that children whose parents are smokers, with low socio-economical status or less educated are at high risk for SHS exposure. ${ }^{8}$ Paternal smoking was related with child age, infants were lesslikely to SHSE. ${ }^{17}$ Children, especially infants and preschool children spend much of their times at home with parents so they were exposed SHS more frequently. An effective way in reducing the SHS exposure among infants is education of parents about the harm of SHS exposure and benefits of keeping their home smoke-free. ${ }^{10}$

We found that SHS exposure of infants at home is 1.9 times more in extended families. There was no clear relationship between family size and SHS exposure of infants at home, in most of the studies. ${ }^{8}$ The odds 
Table 1

Socio-demograpic features and secondhand smoke exposure of infants.

\begin{tabular}{|c|c|c|c|c|c|}
\hline \multirow[t]{2}{*}{ Socio-demographic features } & & \multicolumn{2}{|c|}{ SHS exposure of infants } & \multirow[t]{2}{*}{$\chi^{2}$} & \multirow[t]{2}{*}{$\mathrm{p}$} \\
\hline & & Yes; n (\%) & No; n (\%) & & \\
\hline \multirow[t]{2}{*}{ Residence } & Rural & $159(68.8)$ & $72(31.2)$ & 3.413 & 0.065 \\
\hline & Urban & $329(61.8)$ & $203(38.2)$ & & \\
\hline \multirow[t]{3}{*}{ Mothers' age } & $\leq 19$ years & $38(66.7)$ & $19(33.3)$ & 0.344 & 0.842 \\
\hline & $20-34$ years & $391(63.5)$ & $225(36.5)$ & & \\
\hline & $\geq 35$ years & $59(65.6)$ & $31(34.4)$ & & \\
\hline \multirow[t]{3}{*}{ Fathers' age } & $\leq 19$ years & $3(60.0)$ & $2(40.0)$ & 0.276 & 0.871 \\
\hline & $20-34$ years & $351(64.5)$ & $193(34.5)$ & & \\
\hline & $\geq 35$ years & $134(62 ., 6)$ & $80(37.4)$ & & \\
\hline \multirow[t]{2}{*}{ Family type } & Extended & $92(72.4)$ & $35(27.6)$ & 4.756 & 0.029 \\
\hline & Core & $396(62.3)$ & $240(37.7)$ & & \\
\hline \multirow[t]{2}{*}{ Household count $^{\mathrm{b}}$} & $\leq 4$ & $326(61.9)$ & $201(38.1)$ & 2.982 & 0.084 \\
\hline & $\geq 5$ & $161(68.4)$ & $74(31.6)$ & & \\
\hline \multirow[t]{2}{*}{ Consanguineous mariage } & Yes & $38(52.1)$ & 35 (47.9) & 4.962 & 0.026 \\
\hline & No & $450(65.2)$ & $240(34.8)$ & & \\
\hline \multirow[t]{2}{*}{ Mothers' education } & $\leq 8$ years & $301(68.4)$ & 139 (31.6) & 8.933 & 0.003 \\
\hline & $\geq 9$ years & 187 (57.9) & $136(42.1)$ & & \\
\hline \multirow[t]{2}{*}{ Fathers' education ${ }^{\mathrm{a}}$} & $\leq 8$ years & $243(66.2)$ & $124(33.8)$ & 1.766 & 0.184 \\
\hline & $\geq 9$ years & $242(61.6)$ & $151(38.4)$ & & \\
\hline \multirow[t]{2}{*}{ Mothers' employment } & Employeed & $43(46.2)$ & $50(53.8)$ & 14.429 & 0.001 \\
\hline & Unemployeed & $445(66.4)$ & $225(33.6)$ & & \\
\hline \multirow[t]{2}{*}{ Fathers' employement ${ }^{\mathrm{a}}$} & Employeed & 435 (63.5) & $251(36.5)$ & 0.927 & 0.629 \\
\hline & Unemployeed & $52(68.4)$ & $24(31.6)$ & & \\
\hline \multirow[t]{2}{*}{ Health insurance } & Yes & $22(84.6)$ & $4(15.4)$ & 4.983 & 0.026 \\
\hline & No & $466(63.2)$ & $271(36.8)$ & & \\
\hline \multirow[t]{2}{*}{ Monthly income ${ }^{c}$} & Inadequate & $310(67.4)$ & $150(32.6)$ & 0.654 & 0.017 \\
\hline & Adequate & $178(58.9)$ & $124(41.1)$ & & \\
\hline Total & & $488(64.0)$ & $275(36.0)$ & & \\
\hline
\end{tabular}

a 3 date missing.

b 2 data missing.

c 1 data missing.

Table 2

Bio-demographic features and secondhand smoke exposure of infants.

\begin{tabular}{|c|c|c|c|c|c|}
\hline \multicolumn{2}{|c|}{ Bio-demographic features } & \multicolumn{2}{|c|}{ SHS exposure of infants } & \multirow[t]{3}{*}{$\chi^{2}$} & \multirow[t]{3}{*}{$\mathrm{p}$} \\
\hline & & \multirow{2}{*}{$\frac{\text { Yes }}{\mathrm{n}(\%)}$} & No & & \\
\hline & & & n (\%) & & \\
\hline \multirow[t]{3}{*}{ Pregnancy count } & 1 & $170(64.4)$ & $94(35.6)$ & 2.035 & 0.361 \\
\hline & 2 & $146(60.6)$ & $95(39.4)$ & & \\
\hline & 3 or more & $172(66.7)$ & $86(33.3)$ & & \\
\hline \multirow[t]{3}{*}{ Antenatal care count } & 1 & $27(64.3)$ & $15(35.7)$ & 2.970 & 0.226 \\
\hline & 2 & $289(66.4)$ & $146(33.6)$ & & \\
\hline & 3 or more & $172(60.1)$ & $114(39.9)$ & & \\
\hline \multirow[t]{3}{*}{ Infants' age (month) } & $\leq 2$ months & $112(56.6)$ & $86(43.4)$ & 7.764 & 0.021 \\
\hline & 3-4 months & $260(65.0)$ & $140(35.0)$ & & \\
\hline & $\geq 5$ months & $116(70.3)$ & $49(29.7)$ & & \\
\hline \multirow{2}{*}{$\begin{array}{l}\text { Mothers' smoking } \\
\text { status }\end{array}$} & Smoker & $64(90.1)$ & $7(9.9)$ & 23.281 & 0.001 \\
\hline & Non-smoker & $424(61.3)$ & $268(38.7)$ & & \\
\hline \multirow{2}{*}{$\begin{array}{l}\text { Fathers' smoking } \\
\text { status }\end{array}$} & Smoker & $392(84.3)$ & $73(15.7)$ & 213.741 & 0.001 \\
\hline & Non-smoker & $96(32.2)$ & $202(67.8)$ & & \\
\hline \multirow[t]{2}{*}{ Total } & & 488 & 275 & & \\
\hline & & $(64.0)$ & $(36.0)$ & & \\
\hline
\end{tabular}

of SHSE at home was ranges between 1,2-1,72 in different studies. ${ }^{16,18,19}$ But due to the non-standardized measurement techniques, debating results were reported in studies. ${ }^{8}$ Children living in extended families were exposed to SHS at home more because of the presence of smoking grandparents and family members other than parents. On the other hand, family size and low socio-economical level are closely associated each other. Low socio-economical levels are related with poorer health outcomes, morbidities and mortality. It was shown that the prevalence of smoking is higher in less educated groups and with low socio-economical status. ${ }^{20,21}$

In our study, it was demonstrated that SHS exposure of infants increase as they grow up. The SHS exposure of infants at home is 2.1
Table 3

Related factors of secondhand smoke exposure of infants at home.

\begin{tabular}{llll}
\hline \multicolumn{2}{l}{ Depended variable: secondhand smoke exposure of infants at home } & \\
\hline Independent variables & & Odds Ratio & $\% 95$ CI \\
\hline \multirow{2}{*}{ Mothers' education } & $\leq 8$ years & $\mathbf{1 . 7}$ & $\mathbf{1 . 2 - 2 . 4}$ \\
& $\geq 9$ years & 1 (Reference) & \\
Family type & Extended family & $\mathbf{1 . 9}$ & $\mathbf{1 . 1}-\mathbf{3 . 1}$ \\
& Nuclear family & 1 (Reference) & \\
Fathers' smoking status & Smoker & $\mathbf{1 1 . 3}$ & $\mathbf{7 . 8}-\mathbf{1 6 . 2}$ \\
& Non-smoker & 1 (Reference) & \\
Mothers' smoking status & Smoker & $\mathbf{5 . 0}$ & $\mathbf{2 . 1}-\mathbf{1 2 . 1}$ \\
& Non-smoker & 1 (Reference) & \\
Infants' age (months) & $\geq 5$ months & $\mathbf{2 . 1}$ & $\mathbf{1 . 2 - 3 . 5}$ \\
& $3-4$ months & 1.4 & $0.9-2.2$ \\
& $\leq 2$ months & 1 (Reference) & \\
& &
\end{tabular}

times more in ones with the age of $\geq 5$ months compared to infants $\leq 2$ months old. A study form Iran revealed that SHS exposure of infants at home increased 1.19 times as they grew up. ${ }^{22}$ This relationship was also shown in other studies from Mongolia and Greece. ${ }^{23,24}$ In a recent study with measurement of cotinine levels it was shown that urinary cotinine levels was significantly increase per one month up to 1 years. ${ }^{22}$ The majority of preventive health measures are taking into account the first weeks and months after birth. During this period, parents mainly contact with health professionals and are warned about SHS exposure. ${ }^{25}$ As children grow up, parents care less about SHS exposure of infant at home due to idea that children get increased tolerance to smoke by time. $^{26}$

Most of the studies from different countries reported significant association between low educational level and increased SHS exposure risk. We found that SHS exposure of infants at home is 1.7 time more if mothers' education was 8 years or below. In study from Thailand, it was indicated that the SHS exposure rate of infants decreases with the 
increase of educational level of parents. ${ }^{27}$ Chen et al. from USA reported an inverse correlation between maternal education level and urinary cotinine levels of children. ${ }^{28}$ The educational level was directly related with socio-economical status of parents. It was reported that the prevalence of smoking in higher social classes are less than lower social groups, moreover parents with lower education levels have fewer health promoting behaviors. ${ }^{20,21}$

The study group included only very young children $(<12$ months of age). This is the strongest part of the study because there were very few studies including this group of age. Although other studies included infants within their samples, there are only three studies composed of only infants with this age group. ${ }^{8}$ Our study was carried out in a city of Turkey and this is one of the limitations of our study. This survey should be carried out with a larger sample size to be able to reflect the national data. Second limitation is the determination method of SHS exposure, an objective method like measuring urinary or salivary cotinine levels would make the results more unbiased.

In conclusion, the rate of SHS expose of infants at home is high. The main predictors of SHS exposure are parents' smoking status, mothers' educational level, family type and infants' age. The most important factor affecting SHS exposure was parents'; especially fathers' smoking status. Therefore parents should be encouraged to quit smoking. If parents are unable to stop smoking, they should be promoted to live in smoke free homes.

\section{Conflicts of interest}

None.

\section{Appendix A. Supplementary data}

Supplementary data to this article can be found online at https:// doi.org/10.1016/j.cegh.2019.08.011.

\section{References}

1. Jarvie JA, Malone RE. Children's secondhand smoke exposure in private homes and cars: an ethical analysis. Am J Public Health. 2008;98(12):2140-2143.

2. Raghuveer G, White DA, Hayman LL, et al. Cardiovascular consequences of childhood secondhand tobacco smoke exposure: prevailing evidence, burden, and racial and socioeconomic disparities: a scientific statement from the American heart association. Circulation. 2016;134(16):e336-e359. https://doi.org/10.1161/CIR. 0000000000000443.

3. Global Youth Tabacco Survey Collaborative Group. Tobacco use among youth: a cross country comparison. Tob Control. 2002;11(3):252-270.

4. Yao T, Sung H, Wang Y, Lightwood J, Max W. Sociodemographic differences among US children and adults exposed to secondhand smoke at home: national Health Interview Surveys 2000 and 2010. Public Health Rep. 2016;131:357-366.

5. West HW, Juonala M, Gall SL, et al. Exposure to parental smoking in childhood is associated with increased risk of carotid atherosclerotic plaque in adulthood: the Cardiovascular Risk in Young Finns Study. Circulation. 2015;131(14):1239-1246.

6. Kuntz B, Lampert T. Social disparities in parental smoking and young children's exposure to secondhand smoke at home: a time-trend analysis of repeated cross- secitonal data from German KiGGS study between 2003-2006 and 2009-2012. BMC Public Health. 2016;16:488. https://doi.org/10.0186/s12889-016-3175-x.

7. Mbulo L, Palipudi KM, Andes L, et al. Secondhand smoke exposure at home among one billion children in 21 countires: findings from the Global Adult Tobacco Survey (GATS). Tob Control. 2016;25(e2):e95-e100. https://doi.org/10.1136/ tobaccocontrol-2015-052693.

8. Orton S, Jones LL, Cooper S, Lewis S, Coleman T. Predictors of children's secondhand smoke exposure at home: a systematic review and narrative synthesis of the evidence. PLoS One. 2014;9(11):e112690.

9. Homa DM, Neff LJ, King BA, et al. MMWR Morb Mortal Wkly Rep. 2015;64(4):103-108.

10. Pisinger C, Hammer-Helmich L, Andreasen AH, Jorgensen T, Glumer C. Social disparities in children's exposure to second hand smoke at home: a repeated crosssectional survey. Environ Health. 2012;17(11):65.

11. Bilir N, Çakır B, Dağlı E, Ergüder T, Önder Z. Tobacco Control in Turkey. Copenhagen Denmark: World Health Organization; 2009.

12. Erguder T, Cakır B, Aslan D, Warren CW, Jones NR, Asma S. Evaluation of the use of Global Youth Tobacco Survey (GYTS) data for developing evidence-based tobacco control policies in Turkey. BMC Public Health. 2008;8(S1):4. https://doi.org/10. 1186/1471-2458-8-S1-S4.

13. Boyaci H, Etiler N, Duman C, Basyigit I, Pala A. Environmental tobacco smoke exposure in school children: parent report and urine cotinine measures. Pediatr Int. 2006;48(4):382-389.

14. Cobanoglu N, Kiper N, Dilber E, et al. Environmental tobacco smoke exposure and respiratory morbidity in children. Inhal Toxicol. 2007;19(9):779-785.

15. Oberg M, Jaakkola M, Woodward A, Peruga A, Pruss-Ustun A. Worldwide burden of disease from exposure to second-hand smoke: a retrospective analysis of data from 192 countries. Lancet. 2011;377:139-146.

16. Ulbricht S, Holdys J, Meyer C, Kastirke N, Haug S, John U. Predictors of indoor smoking at young children's home: a cross-sectional study. Eur J Pediatr. 2014;173(9):1187-1191. https://doi.org/10.1007/s00431-014-2310-x.

17. Borland R, Yong HH, Cummings KM, Hyland A, Anderson S, Fong GT. Determinants and consequences of smoke-free homes: findings from the international tobacco control (ITC) four country. Surv Tob Control. 2006;15:42-50.

18. Hawkins S, Berkman L. Identifying infants at high-risk for second-hand smoke exposure. Child Care Health Dev. 2014;40(3):441-445.

19. Longman JM, Passey ME. Children, smoking households and exposure to secondhand smoke in the home in rural Australia: analysis of a national cross-sectional survey. BMJ open. 2013;3(7):e003128.

20. Wang YT, Tsai YW, Tsai T, Chang PY. Children's exposure to secondhand smoke at home before and after smoke-free legislation in Taiwan. Tob Control. 2016;26(6):690-696. https://doi.org/10.1136/tobaccocontrol-2016-053039.

21. Adler NE, Newman K. Socioeconomic disparities in health: pathways and policies. Health Aff. 2002;21:60-76.

22. Baheiraei A, Kharaghani R, Mohsenifar A, et al. Factors associated with Secondhand smoke exposure in infants. Tannaffos. 2010;9(2):43-49.

23. Rachiotis G, Siziya S, Muula AS, Rudatsikira E, Papastergiou P, et al. Determinants of exposure to environmental tobacco smoke (ETS) among non smoking adloecents (aged 11-17 years old) in Grecee: results from the 2004-2005 GYTS study. Int $J$ Environ Res Public Health. 2010;7:284-290.

24. Rudatsikira E, Siziya S, Dondong J, Muula AS. Prevelance and coorelates of environmental tobacco smoke exposure among adolescents in Mongolia. Indian J Pediatr. 2007;74:1089-1093.

25. Ino T, Shibuya T, Saito K, Ohshima J, Okada R. A passive smoking screening program for children. Prev Med. 2006;42(6):427-429.

26. Robinson J, Kirkcaldy AJ. Imagine all that smoke in their lungs': parentes' perceptions of young childrens' tolerance of tobacco smoke. Health Educ Res. 2009;24(1):11-21.

27. Anutaseree W, Mo-Suwan L, Ovatlarnporn C, Tantana C, Ma-a-Lee A. Exposure to environmental tobacco smoke among infants in southern Thailand: a study of urinary cotinine. Bull Environ Contam Toxicol. 2008;80(1):34-37.

28. Chen X, Stanton B, Hopper J, Khankari N. Sources, locations and predictors of environmental tobacco smoke exposure among young children from inner city families. $J$ of Pediatric Healthcare. 2011;25:365-372. 